\title{
Differences in clinical characteristics and tumor prognosis between primary and secondary conventional pelvic chondrosarcoma
}

\author{
Jie Zang, Wei Guo*, Rongli Yang, Xiaodong Tang and Haijie Liang
}

\begin{abstract}
Background: Chondrosarcoma (CS) most commonly involves the pelvis. This study aimed to analyze differences in clinical characteristics and prognostic factors between primary and secondary conventional pelvic CS, and provide reference for clinical diagnosis and treatment.

Methods: Eighty patients (54 primary cases and 26 secondary cases) with pelvic CS were included in this retrospective study. The tumor site, Enneking stage, soft tissue mass, margin, initial tumor grade, incidence of local recurrence and distant metastasis were evaluated. Kaplan-Meier method was used to calculate the overall survival rate. $X^{2}$ test and logrank test were used for univariate analysis, and Cox test was used in multivariate analysis.

Results: The average age of patients with secondary CS was significantly younger than that of patients with primary CS $(P<0.001)$. The soft tissue mass of patients with secondary CS was significantly larger than that of patients with primary CS $(P=0.002)$. There was a significant difference in initial tumor pathologic grade between the two groups $(P=0.002)$. No statistically significant difference was observed in the local recurrence rate between the two groups. The median recurrence time of patients with primary CS after the first treatment was significantly shorter than that of patients with secondary CS $(P<0.001)$. The overall survival rate of patients with secondary CS was much higher than that of patients with primary CS $(P=0.003)$. Cox regression analysis showed that the initial tumor grade was an independent factor in the overall survival rate of patients with CS.
\end{abstract}

Conclusion: There were significant differences in age, soft tissue mass, initial tumor grade, and overall survival rate between the two groups. The overall survival rate of pelvic CS was related to the initial tumor grade of CS.

Keywords: Chondrosarcoma, Primary, Secondary, Pelvis

\section{Background}

Chondrosarcoma (CS) is a malignant cartilaginous matrixproducing bone tumor [1]. Its incidence is only next to that of osteosarcoma, accounting for $17-24 \%$ of malignant bone tumors. The pelvis is involved in about $22-39 \%$ of CS patients [2, 3]. CS has many subtypes, among which

* Correspondence: Bonetumorguo@gmail.com

Musculoskeletal Tumor Center, Peking University People's Hospital, No.11 Xizhimen South Street, Xicheng District, Beijing 100044, China conventional CS is the most common, accounting for more than $90 \%$ of CS cases [4]. According to pathological classification, conventional CS can be divided into grade I to III. Primary CS occurs in the bone without a pre-existing lesion. If the tumor develops from a pre-existing benign tumor such as osteochondroma or enchondroma, it is called secondary CS. From its location, it can further be divided into the central type and peripheral type. The former occurs in the marrow cavity, while the latter occurs in the bone surface, generally

(c) The Author(s). 2020 Open Access This article is licensed under a Creative Commons Attribution 4.0 International License, which permits use, sharing, adaptation, distribution and reproduction in any medium or format, as long as you give appropriate credit to the original author(s) and the source, provide a link to the Creative Commons licence, and indicate if changes were made. The images or other third party material in this article are included in the article's Creative Commons licence, unless indicated otherwise in a credit line to the material. If material is not included in the article's Creative Commons licence and your intended use is not permitted by statutory regulation or exceeds the permitted use, you will need to obtain permission directly from the copyright holder. To view a copy of this licence, visit http://creativecommons.org/licenses/by/4.0/ The Creative Commons Public Domain Dedication waiver (http://creativecommons.org/publicdomain/zero/1.0/) applies to the data made available in this article, unless otherwise stated in a credit line to the data. 
from the cartilage cap of an osteochondroma [5]. Primary CS is always central and has early onset characteristics, a high degree of malignancy, rapid development, and a poor prognosis [6]. It is mainly found in adults and older people, and the incidence rate in males is higher than that in females [7-10]. Secondary CS is rare, and the literature on secondary CS is relatively limited. It could be central or peripheral, and has the characteristics of late onset, slow development, and a good prognosis. It needs clinical, imaging, anatomical, and pathological analysis to make a correct diagnosis and histological classification. In a retrospective analysis of 107 patients with secondary CS, Adel et al. found that patients with secondary CS were 1-20 years younger than those with primary CS. The local recurrence rates of patients with secondary CS were 15.9 and $17.5 \%$ at 5 and 10 years. The 5 -year and 10 year mortality rates of patients receiving the first treatment were 1.6 and $4.8 \%$, respectively [11]. However, a direct comparison between primary and secondary CS in clinical characteristics has not been reported.

CS is not sensitive to radiotherapy and chemotherapy, and surgical treatment is the primary treatment [1]. Previous studies have shown that en bloc resection with an adequate surgical margin is necessary to achieve local control in any pathological tumor grades [7, 12]. However, pelvic CS is large, complex in local structure, and adjacent to blood vessels and nerve bundles, making it very difficult to operate $[8,13,14]$. It has been reported that the prognostic factors include tumor grade, tumor size, surgical margin, and tumor type (primary or secondary tumors) $[7-9,15]$. However, these reports contain other pathological subtypes, and there is no direct comparison of tumor prognosis between primary and secondary CS.

In this study, we retrospectively analyzed 80 patients with pelvic CS to explore the differences in clinical characteristics, local control rate, overall survival rate, and prognostic risk factors between primary and secondary conventional pelvic CS.

\section{Methods}

A total of 142 cases of pathologically confirmed pelvic CS in our hospital from 2006 to 2018 were collected. Among them, 18 patients were excluded because the first treatment was received in other hospitals. Sixteen cases of dedifferentiated subtype, 4 cases of periosteal type, 4 cases of mesenchymal type and 2 cases of clear cell type were excluded. Thereafter, 6 patients did not have complete clinical data, and 12 patients were lost to follow-up. Finally, 80 cases of conventional CS were included in the study, including 54 cases of primary CS and 26 cases of secondary CS (Fig. 1). All patients with secondary CS received a previous pathological diagnosis of benign chondropathy, and were followed up by our hospital before the diagnosis of secondary CS. In the secondary CS group, CS originated from enchondromas in 4 cases, osteochondromas in 8 cases, Ollier disease in 4 cases, and multiple osteochondromas in 10 cases.

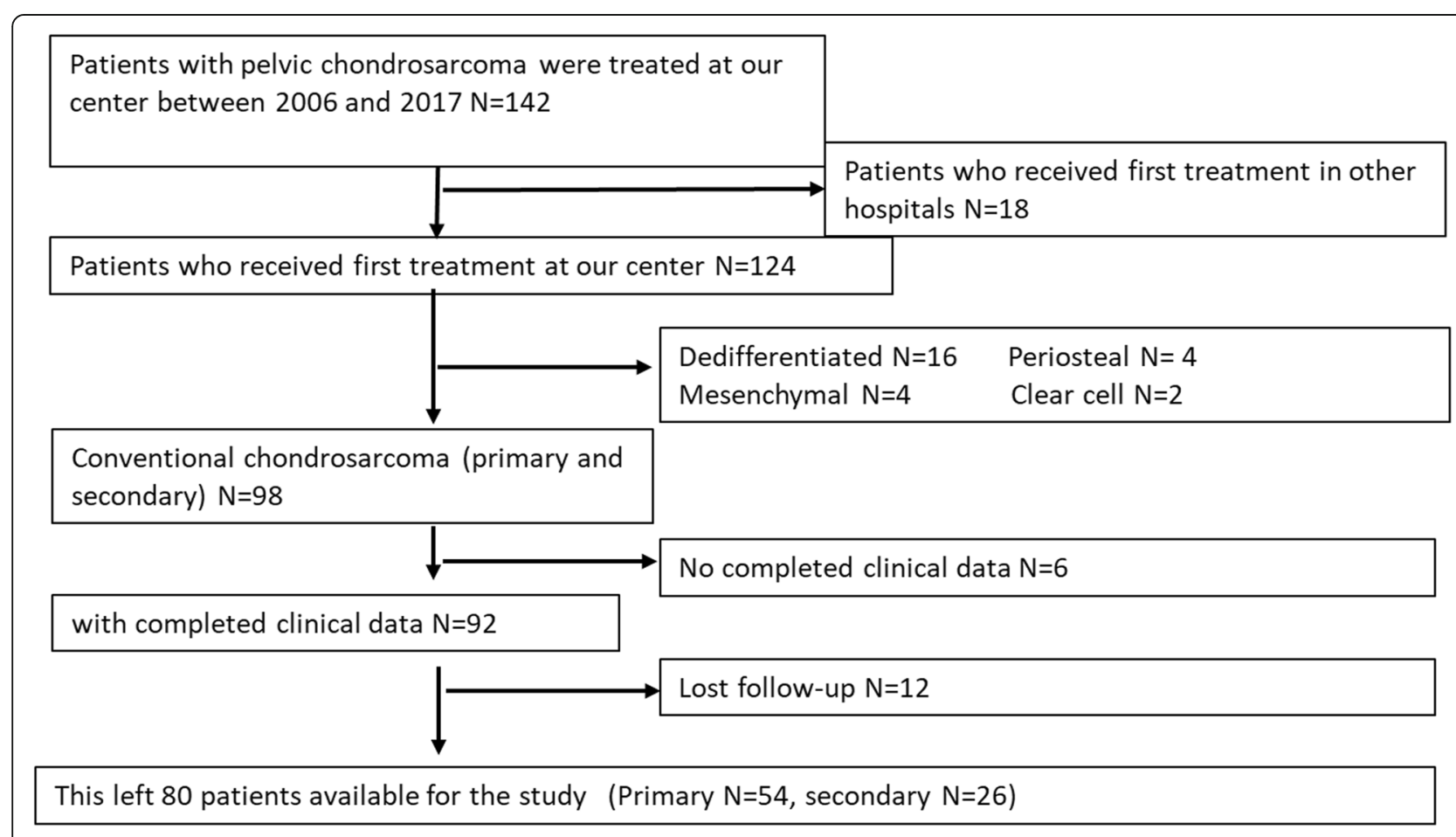

Fig. 1 The study flowchart 
According to the pathological results, combined with clinical and imaging data, the tumor's surgical stage was determined according to the Enneking malignant tumor classification [16] to determine the optimal treatment plan. The histological classification was made according to the system proposed by Evans et al. [17]. According to the Enneking classification [18], the surgical margin was determined, which included intralesional, marginal, and wide margins.

Within two years after the operation, the patients were followed up every three months by visit to the outpatient department. The X-ray films of the operation site were rechecked, and CT or MRI was performed as required.

Table 1 Comparison of primary and secondary chondrosarcoma of pelvis in terms of clinical characteristics

\begin{tabular}{|c|c|c|c|c|}
\hline Variable & & Primary & Secondary & $P$ \\
\hline \multirow[t]{2}{*}{ Gender } & Male & $29(53.7 \%)$ & $18(69.2 \%)$ & 0.23 \\
\hline & Female & $25(46.3 \%)$ & $8(30.8 \%)$ & \\
\hline \multirow[t]{3}{*}{ Age } & Mean \pm SD (years) & $48.5 \pm 12.8$ & $32.2 \pm 8.8$ & 0.000 \\
\hline & $<40$ (years) & $11(20.4 \%)$ & $21(80.8 \%)$ & 0.000 \\
\hline & $\geq 40$ (years) & $43(79.6 \%)$ & 5 (19.2\%) & \\
\hline Tumor Site & । & $5(9.3 \%)$ & 7 (26.9\%) & 0.023 \\
\hline |:illium & $1+P$ & $6(11.1)$ & $2(7.7 \%)$ & \\
\hline P:periacetabulum & $I+P+I-P$ & $10(18.5 \%)$ & $1(3.8 \%)$ & \\
\hline I-P:ischium-pubis & $I+P+I-P+S$ & $2(3.7 \%)$ & 0 & \\
\hline F:femoral & $I+P+I-P+F$ & $1(1.9 \%)$ & 0 & \\
\hline \multirow[t]{7}{*}{ S:sacrum } & $I+P+S$ & $1(1.9 \%)$ & 0 & \\
\hline & $1+S$ & $1(1.9 \%)$ & 0 & \\
\hline & $P$ & $3(5.6 \%)$ & $1(3.8 \%)$ & \\
\hline & $P+I-P$ & $25(46 \%)$ & $9(34.6 \%)$ & \\
\hline & $P+I-P+F$ & 0 & $1(3.8 \%)$ & \\
\hline & $1+P$ & 0 & $4(15.4 \%)$ & \\
\hline & $I+P+F$ & 0 & $1(3.8 \%)$ & \\
\hline \multirow[t]{5}{*}{ Enneking Stage } & $\mathrm{IA}$ & $1(1.9 \%)$ & $2(7.7 \%)$ & 0.439 \\
\hline & IB & $3(5.6 \%)$ & $2(7.7 \%)$ & \\
\hline & $\| A$ & $6(11.1 \%)$ & $1(3.8 \%)$ & \\
\hline & $\| \mathrm{B}$ & $40(74.1 \%)$ & $21(80.8 \%)$ & \\
\hline & III & $4(7.4 \%)$ & 0 & \\
\hline \multirow[t]{3}{*}{ Soft Tissue Mass } & Mean \pm SD $(\mathrm{cm})$ & $6.6 \pm 4.3$ & $10.6 \pm 4.5$ & 0.002 \\
\hline & $<8 \mathrm{~cm}$ & $29(53.7 \%)$ & $8(30.8 \%)$ & 0.016 \\
\hline & $\geq 8 \mathrm{~cm}$ & $25(46.3 \%)$ & $18(69.2 \%)$ & \\
\hline \multirow[t]{3}{*}{ Margin } & Wide & $22(40.7 \%)$ & $10(38.5 \%)$ & 0.809 \\
\hline & Marginal & $19(35.2 \%)$ & $8(30.8 \%)$ & \\
\hline & Intralesional & $13(24.3 \%)$ & $8(30.8 \%)$ & \\
\hline \multirow[t]{3}{*}{ Initial Tumor Grade } & I & $4(7.4 \%)$ & 7 (26.9\%) & 0.002 \\
\hline & $\|$ & $38(70.4 \%)$ & 19 (73.1\%) & \\
\hline & III & $12(22.2 \%)$ & 0 & \\
\hline
\end{tabular}

Table 2 Comparison of postoperative follow-up results of primary and secondary pelvic chondrosarcoma

\begin{tabular}{llll}
\hline Variable & Primary & Secondary & $P$ \\
\hline Alive without disease & 27 & $17(65.4 \%)$ & 0.016 \\
Alive with disease & $(50 \%)$ & & \\
Death & $3(5.6 \%)$ & $5(19.2 \%)$ & \\
& 24 & $4(15.4 \%)$ & \\
Postoperative hemorrhage & $(44.4 \%)$ & & \\
(perioperative period) & $1(1.9 \%)$ & 0 \\
Septic shock (perioperative) & $1(1.9 \%)$ & 0 \\
Cerebral hemorrhage & $2(3.7 \%)$ & 0 \\
Myocardial infarction & $1(1.9 \%)$ & 0 & \\
pulmonary embolism & $1(1.9 \%)$ & 0 & \\
Pulmonary metastasis & 12 & $2(7.7 \%)$ & \\
Cachexia & $(22.2 \%)$ & & \\
Brain metastases & $4(7.4 \%)$ & $2(7.7 \%)$ & \\
Follow-up time & $2(3.7 \%)$ & 0 & \\
Mean \pm SD (Months) & & & \\
& $40 \pm$ & $68.8 \pm 38.6$ & 0.002 \\
\hline
\end{tabular}

Chest X-ray or CT scan was used to determine whether there was lung metastasis, and whole-body bone scan was used to determine whether there was bone metastasis. If there was no sign of progression, the patients were followed up every six months after two years and yearly after five years. The follow-up records included local recurrence and distant metastasis. If the patient died, the time of death was confirmed by telephone follow-up. The follow-up time was defined from the beginning of diagnosis to the end of death or statistics.

\section{Statistical analysis}

IBM SPSS statistics 24.0 software was used for data collection and statistical analysis. Pearson $\chi 2$ test was used to test the correlation between two classification variables. If the frequency was $<5$, Fisher exact probability method was used. The 5-year and 10-year overall survival estimated by Kaplan-Meier method was defined as the time from the beginning of diagnosis to the end of disease-related death and was censored at the date of the latest follow-up or death due to other causes. Cox regression model was used to analyze the survival time. When these variables were included in Cox regression model for multivariate analysis, the forward method based on maximum likelihood estimation was used for independent variable selection. $P<0.05$ indicated statistically significant difference.

\section{Results}

Clinical characteristics of pelvic CS

The majority of patients with primary pelvic CS were over 40 years old $(79.6 \%)$ while only $19.2 \%$ patients with 
Table 3 Comparison of primary and secondary chondrosarcoma of pelvis in terms of local recurrence

\begin{tabular}{|c|c|c|c|c|}
\hline Variable & & Primary & Secondary & $P$ \\
\hline \multirow[t]{2}{*}{ Local recurrence,n(\%) } & No & $34(63.0)$ & $17(65.4)$ & 0.436 \\
\hline & Yes & $20(37.0)$ & $9(34.6)$ & \\
\hline Recurrence time after first treatment (months) & Median (IQR) & $14.0(8.0-21.8)$ & $38.5(25.0-59.5)$ & $<0.001$ \\
\hline \multirow[t]{2}{*}{ Pathological progression after recurrence ${ }^{a}, n(\%)$} & No & $7(58.3)$ & $5(55.6)$ & 1.000 \\
\hline & Yes & $5(41.7)$ & $4(44.4)$ & \\
\hline
\end{tabular}

${ }^{a}$ Received second surgical treatment: Primary $N=12$; secondary $N=9$

$I Q R$ interquartile range

secondary pelvic CS were over 40 years old $(P<0.001)$. Among both the primary and secondary CS groups, the periacetabulum and ischium-pubis was the most common tumor site, which was 46 and $34.6 \%$, respectively $(P=0.023)$. The average diameter of primary soft tissue mass was $6.6 \pm 4.3 \mathrm{~cm}$, much shorter than that of secondary soft tissue mass $(10.6 \pm 4.5 \mathrm{~cm}) \quad(P=0.002)$. Moreover, $53.7 \%$ of primary CS patients had a tumor diameter $<8 \mathrm{~cm}$, while only $30.8 \%$ of secondary CS patients had a tumor diameter $<8 \mathrm{~cm}$. In the primary CS group, 4 cases of patients had lung metastases and were classified as stage III. The remaining 50 cases had localized diseases. In the secondary CS group, no case had lung metastasis and all the 26 cases had localized diseases. In the secondary CS patients, $26.9 \%$ had grade I CS initially versus $7.4 \%$ in the primary CS patients. In addition, $22.2 \%$ of primary CS patients had grade III CS while no secondary CS patients had grade III CS. There was no significant difference in Enneking stage and margin between the two groups (Table 1).

\section{Follow-up results of pelvic CS}

The follow-up results showed that the disease-free survival rate and overall survival rate were 50 and
$55.6 \%$ for patients with primary CS, and 65.4 and $84.6 \%$ for patients with secondary CS, respectively. The difference in survival rate between the two groups was significant $(P=0.016)$. The mortality rate of patients with primary CS was $44.4 \%$. Among them, 2 cases died during the perioperative period (1 case died of cerebral hemorrhage, and 1 case died of septic shock), 2 cases died of cerebral hemorrhage, 1 case died of myocardial infarction, and 1 case died of pulmonary embolism. Twelve cases died of lung metastasis, 4 cases died of cachexia and 2 cases died of brain metastasis. The mortality rate of secondary CS patients was only $15.4 \%$, among whom 2 died of cachexia, and 2 died of lung metastasis. The mean followup duration was $40.0 \pm 28.2$ months for primary CS patients and $68.8 \pm 38.6$ months for secondary CS patients (Table 2).

\section{Local recurrence of pelvic CS}

The diagnosis of local recurrence includes CT, MRI, PET-CT and biopsy. In this study, 20 patients (37.0\%) with primary pelvic CS and 9 patients (34.6\%) with secondary pelvic CS had local recurrence, and there was no statistically significant difference between the two

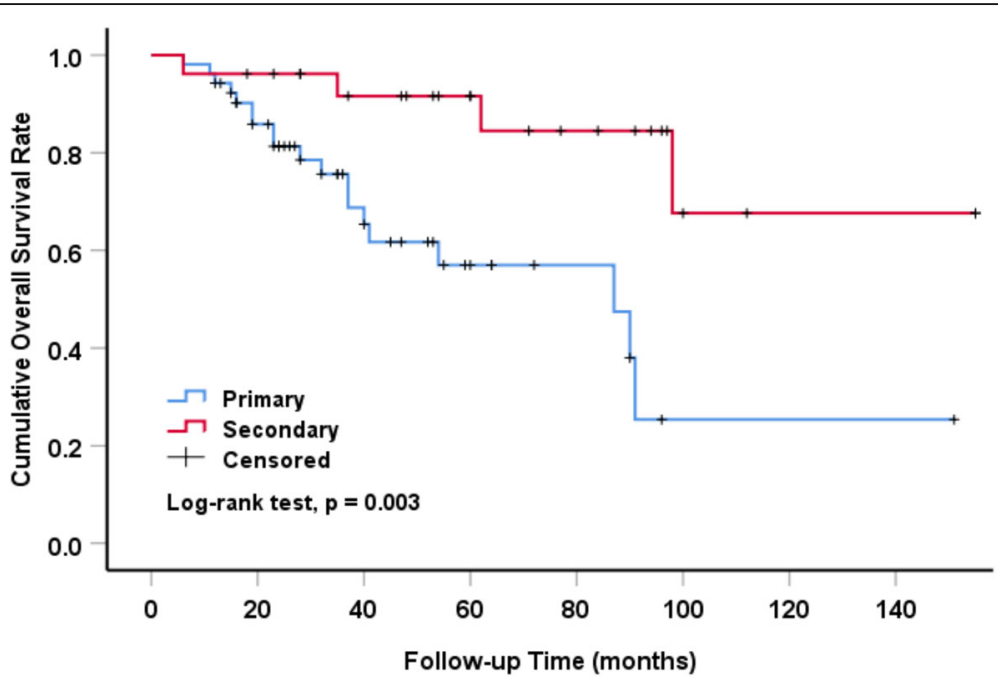

Fig. 2 Overall survival of primary and secondary pelvic CS 


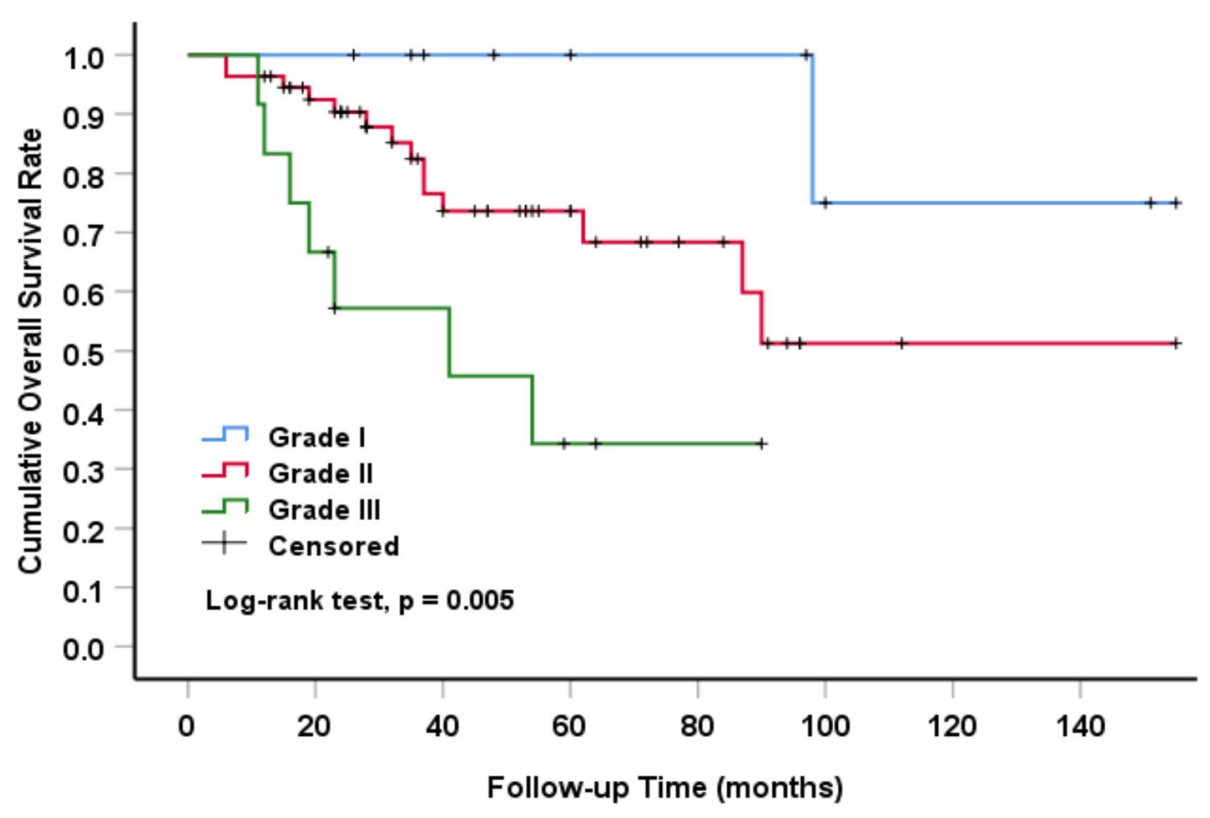

Fig. 3 Effect of initial tumor classification on survival of patients with pelvic CS

groups. Surgical pathological examination revealed that of the 20 patients who relapsed in the primary CS group, 1 was grade I, 14 were grade II, and 5 were grade III. Nine patients relapsed in the secondary CS group, $3 \mathrm{had}$ grade I pathology after the initial operation, and 6 had grade II pathology. The median recurrence time of primary CS patients after the first treatment was 14 months, which was significantly shorter than that of secondary patients $(P<0.001)$ (Table 3$)$.

\section{Prognosis of pelvic CS}

The overall survival rate estimated by Kaplan-Meier method of primary and secondary pelvic CS patients was significantly different $(P=0.003)$ (Fig. 2$)$. The 5 -year and 10-year survival rates of primary CS patients were 57 and $25.3 \%$, respectively. The 5-year and 10-year overall survival rates of secondary CS patients were much higher than those of primary patients, which were 91.6 and $67.6 \%$, respectively. The overall survival time of patients with pelvic CS was analyzed by univariate analysis, and the variables included initial tumor grade. The survival rate was $100 \%$ in grade I, $73.6 \%$ in grade II and $34.3 \%$ in grade III $(P=0.005)$ (Fig. 3$)$. Further multivariate analysis showed that initial tumor grade was an independent prognostic factor. The higher the grade was, the lower the overall survival rate was (Table 4).

\section{Discussion}

The treatment of pelvic CS is a major challenge for surgeons. In this study, we compared primary and secondary conventional pelvic CS patients treated at our center in the past 10 years in terms of clinical characteristics, local recurrence, and overall survival. We also determined the prognostic factor associated with overall survival of patients with CS treated with surgery.

In comparing clinical characteristics, we found significant differences in age of onset, the size of soft tissue mass, and pathological tumor grade between the primary and secondary CS group. In this study, the mean age of primary pelvic CS patients was 48.5 years, and the mean age of secondary pelvic CS patients was 32.2 years. The age in the primary CS group is significant older than that for the secondary CS group. This finding is consistent with previous studies [10]. In this study, we also found that patients with pathological grade II accounted for most patients in the primary and secondary CS groups. Still, no case had pathological grade III secondary CS, which may be related to the small number of cases. The pathological grade of secondary CS patients may be lower than that of primary CS patients. In future work, we will continue to observe whether this conclusion is correct.

In this study, the volume of tumor mass in the secondary CS group was larger than that in the primary CS group, which is similar to the results of Ozaki et al. [19]. Our study also found that tumors secondary to

Table 4 Multivariable analysis designed to analyze independent factors associated with overall survival

\begin{tabular}{llll}
\hline Viable & HR & $\mathbf{9 5 \% ~ C l}$ & $\boldsymbol{P}$ \\
\hline Initial Tumor Grade & & & 0.005 \\
Grade II vs Grade I & 14.837 & $1.110-198.286$ & 0.041 \\
Grade III vs Grade I & 161.445 & $5.954-4377.516$ & 0.003 \\
\hline
\end{tabular}




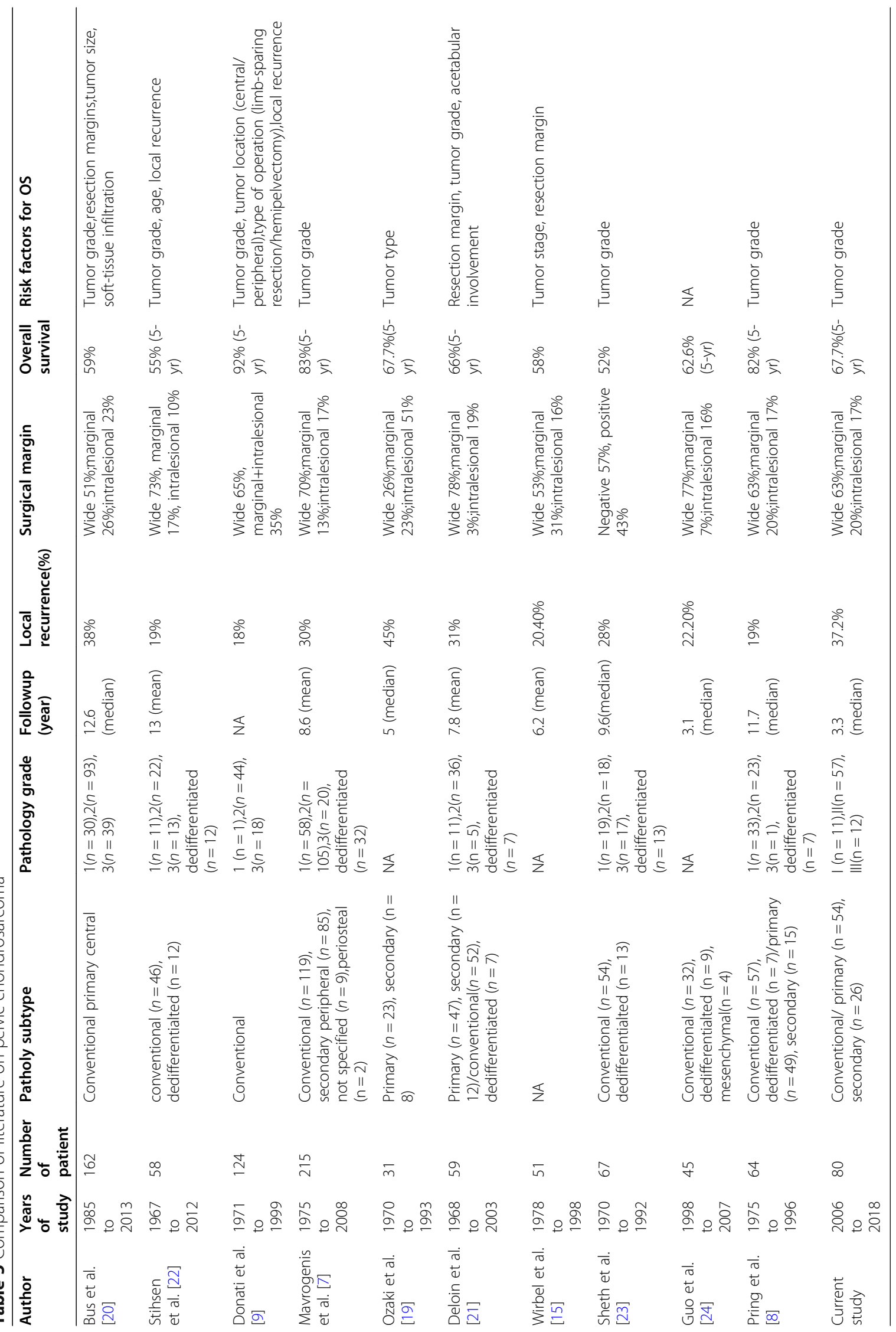


osteochondroma and multiple osteochondromatosis accounted for $70 \%(18 / 26)$ of malignant changes in the pelvis. Of these patients, tumors tend to grow out of bone and form large masses, but they do not destroy the bone cortex. When the tumor grows into the pelvic cavity, it is not easy to show symptoms in the early stage, so the tumor volume is often larger at the time of diagnosis.

According to the literature, the local recurrence rate of pelvic CS is $18-45 \%$ [7-9, 15, 20-23]. In this study, the local recurrence rate of the primary and secondary CS group were 37.0 and $34.6 \%$, respectively. There was no significant difference in the recurrence rate between the two groups, but there was a difference in recurrence time. Among the recurrent cases, grade I accounted for $5 \%$ of the primary CS group and $33.3 \%$ of the secondary CS group. Grade I CS has low malignancy and a slow growth rate, which is the cause of late recurrence in the secondary CS group.

In this study, the prognosis of patients in the secondary CS group was significantly better than that in the primary group, with a 5-year survival rate of 91.6 and 57\% $(P=0.003)$, respectively, which is consistent with the results of Ozaki et al. [19]. Although it has been reported that the prognosis of CS is related to surgical resection margin $[15,20,21]$, tumor size [20], age [22], local recurrence [22], surgical type [9], tumor stage [15], and tumor location $[9,21]$. However, in this study, we conducted a multivariate analysis of all patients with pelvic $C S$ and found that pathological tumor grade, but not tumor type (primary and secondary), was an independent risk factor for prognosis (Table 5). This may be due to the small sample size of this study. In different grades, the prognosis of grade I pelvic CS is the best. The proportion of grade I pelvic CS in the secondary CS group was significantly higher than that in the primary CS group. Therefore, the prognosis of the secondary CS group is significantly better than that of the primary CS group.

There are some limitations in our research. First, the follow-up time is relatively short. CS is characterized by slow growth and late recurrence. Therefore, it is not easy to find a small recurrent tumor due to the influence of surgery and prosthesis. We need to further extend the follow-up duration to observe the difference in recurrence between the two groups. Second, because the samples are difficult to obtain, the sample size difference between the two groups is large, and the total sample size is small. We will conduct studies with larger sample sizes in the future.

\section{Conclusion}

In conclusion, there are differences in age, tumor size, and pathological grade between primary and secondary pelvic CS. There was no difference in local recurrence rate between the two groups. The overall survival rate of patients with secondary pelvic CS was higher than that of patients with primary pelvic CS. The overall survival of pelvic CS was correlated with tumor pathological grade.

\section{Abbreviations}

CS: Chondrosarcoma; LR: Local recurrence; CT: Computed tomography; MRI: Magnetic resonance imaging; PET: Positron emission tomography

\section{Acknowledgements}

None.

\section{Authors' contributions}

$J \mathrm{Z}$ and $\mathrm{W} G$ contributed to the conception and design of the study; $R Y, X T$ and $\mathrm{H} L$ performed the experiments, collected and analyzed data; J Z and $W$ $\mathrm{G}$ wrote the manuscript; All authors reviewed and approved the final version of the manuscript.

\section{Funding}

No funding was received for this study.

\section{Availability of data and materials}

The datasets generated and analyzed during the current study are available from the corresponding author on reasonable request.

\section{Ethics approval and consent to participate}

The study protocol was approved by the Ethics Committee of Peking University People's Hospital. Written informed consent was obtained from all the study subjects before enrollment.

\section{Consent for publication}

Not applicable.

\section{Competing interests}

The authors declare that they have no competing interests.

Received: 17 April 2020 Accepted: 15 October 2020

Published online: 02 November 2020

\section{References}

1. Giuffrida AY, Burgueno JE, Koniaris LG, Gutierrez JC, Duncan R, Scully SP. Chondrosarcoma in the United States (1973 to 2003): an analysis of 2890 cases from the SEER database. J Bone Joint Surg Am. 2009;91(5):1063-72. https://doi.org/10.2106/jbjs.H.00416 PubMed PMID: 19411454. Epub 2009/ 05/05.

2. Fiorenza F, Abudu A, Grimer RJ, Carter SR, Tillman RM, Ayoub K, et al. Risk factors for survival and local control in chondrosarcoma of bone. J Bone Joint Surg Br. 2002;84(1):93-9. https://doi.org/10.1302/0301-620x.84b1.11942 PubMed PMID: 11837841. Epub 2002/02/12

3. Lee FY, Mankin HJ, Fondren G, Gebhardt MC, Springfield DS, Rosenberg AE, et al. Chondrosarcoma of bone: an assessment of outcome. J Bone Joint Surg Am. 1999;81(3):326-38. https://doi.org/10.2106/00004623-19990300000004 PubMed PMID: 10199270. Epub 1999/04/13.

4. Heck RK Jr, Peabody TD, Simon MA. Staging of primary malignancies of bone. CA Cancer J Clin. 2006;56(6):366-75. https://doi.org/10.3322/canjclin. 56.6.366 PubMed PMID: 17135693. Epub 2006/12/01.

5. Benassi MS. Biology of central and peripheral Chondrosarcoma: springer international publishing; 2014.

6. Chow WA. Chondrosarcoma: biology, genetics, and epigenetics. F1000Res. 2018;7. https://doi.org/10.12688/f1000research.15953.1 PubMed PMID: 30519452; PubMed Central PMCID: PMCPMC6248264. Epub 2018/12/07.

7. Mavrogenis AF, Angelini A, Drago G, Merlino B, Ruggieri P. Survival analysis of patients with chondrosarcomas of the pelvis. J Surg Oncol. 2013;108(1):19-27. https://doi.org/10.1002/jso.23351 PubMed PMID: 23681650. Epub 2013/05/18.

8. Pring ME, Weber KL, Unni KK, Sim FH. Chondrosarcoma of the pelvis. A review of sixty-four cases. J Bone Joint Surg Am. 2001;83(11):1630-42 Epub 2001/11/10. PubMed PMID: 11701784.

9. Donati D, El Ghoneimy A, Bertoni F, Di Bella C, Mercuri M. Surgical treatment and outcome of conventional pelvic chondrosarcoma. J Bone 
Joint Surg Br. 2005;87(11):1527-30. https://doi.org/10.1302/0301-620x.87b11. 16621 PubMed PMID: 16260673. Epub 2005/11/02.

10. Altay M, Bayrakci K, Yildiz Y, Erekul S, Saglik Y. Secondary chondrosarcoma in cartilage bone tumors: report of 32 patients. J Orthop Sci. 2007;12(5):415-23. https://doi.org/10.1007/s00776-007-1152-z PubMed PMID: 17909925. Epub 2007/10/03.

11. Ahmed AR, Tan TS, Unni KK, Collins MS, Wenger DE, Sim FH. Secondary Chondrosarcoma in Osteochondroma: report of 107 patients. Clin Orthop Relat Res. 2003:411:193-206.

12. Streitburger A, Ahrens H, Balke M, Buerger H, Winkelmann W, Gosheger G, et al. Grade I chondrosarcoma of bone: the Munster experience. J Cancer Res Clin Oncol. 2009;135(4):543-50. https://doi.org/10.1007/s00432-0080486-z PubMed PMID: 18855011. Epub 2008/10/16.

13. Weber KL, Pring ME, Sim FH. Treatment and outcome of recurrent pelvic chondrosarcoma. Clin Orthop Relat Res. 2002;397:19-28. https://doi.org/10. 1097/00003086-200204000-00004 PubMed PMID: 11953591. Epub 2002/04/16.

14. Kawai A, Healey JH, Boland PJ, Lin PP, Huvos AG, Meyers PA. Prognostic factors for patients with sarcomas of the pelvic bones. Cancer. 1998;82(5): 851-9 Epub 1998/03/05. PubMed PMID: 9486573.

15. Wirbel RJ, Schulte M, Maier B, Koschnik M, Mutschler WE. Chondrosarcoma of the pelvis: oncologic and functional outcome. Sarcoma. 2000;4(4):161-8. https://doi.org/10.1080/13577140020025878 PubMed PMID: 18521296; PubMed Central PMCID: PMCPMC2395445. Epub 2008/06/04.

16. Enneking WF, Spanier SS, Goodman MA. A system for the surgical staging of musculoskeletal sarcoma. Clin Orthop Relat Res. 1980;153:106-20 Epub 1980/11/01. PubMed PMID: 7449206.

17. Evans HL, Ayala AG, Romsdahl MM. Prognostic factors in chondrosarcoma of bone: a clinicopathologic analysis with emphasis on histologic grading. Cancer. 1977;40(2):818-31. https://doi.org/10.1002/1097-0142(197708)40:2<818: aid-cncr2820400234>3.0.co;2-b PubMed PMID: 890662. Epub 1977/08/01.

18. Enneking WF. A system of staging musculoskeletal neoplasms. Clin Orthop Relat Res. 1986;204:9-24 Epub 1986/03/01. PubMed PMID: 3456859.

19. Ozaki T, Hillmann A, Lindner N, Blasius S, Winkelmann W. Chondrosarcoma of the pelvis. Clin Orthop Relat Res. 1997;337:226-39. https://doi.org/10.1097/ 00003086-199704000-00025 PubMed PMID: 9137194. Epub 1997/04/01.

20. Bus MPA, Campanacci DA, Albergo II, Leithner A, van de Sande MAJ, Gaston $\mathrm{CL}$, et al. Conventional primary central Chondrosarcoma of the pelvis: prognostic factors and outcome of surgical treatment in 162 patients. J Bone Joint Surg Am. 2018;100(4):316-25. https://doi.org/10.2106/ jbjs.17.00105 PubMed PMID: 29462035. Epub 2018/02/21.

21. Deloin X, Dumaine V, Biau D, Karoubi M, Babinet A, Tomeno B, et al. Pelvic chondrosarcomas: surgical treatment options. Orthop Traumatol Surg Res. 2009;95(6):393-401. https://doi.org/10.1016/j.otsr.2009.05.004 PubMed PMID: 19801212. Epub 2009/10/06.

22. Stihsen C, Panotopoulos J, Puchner SE, Sevelda F, Kaider A, Windhager R, et al. The outcome of the surgical treatment of pelvic chondrosarcomas: a competing risk analysis of 58 tumours from a single centre. Bone Joint J. 2017;99-b(5):686-96. https://doi.org/10.1302/0301-620x.99b5.Bjj-2016-0761.R PubMed PMID: 28455480. Epub 2017/04/30.

23. Sheth DS, Yasko AW, Johnson ME, Ayala AG, Murray JA, Romsdahl MM. Chondrosarcoma of the pelvis. Prognostic factors for 67 patients treated with definitive surgery. Cancer. 1996;78(4):745-50. https://doi.org/10.1002/ (sici)1097-0142(19960815)78:4<745::Aid-cncr9>3.0.Co;2-d PubMed PMID: 8756367. Epub 1996/08/15.

24. Guo W, Li D, Tang X, Ji T. Surgical treatment of pelvic chondrosarcoma involving periacetabulum. J Surg Oncol. 2010;101(2):160-5.

\section{Publisher's Note}

Springer Nature remains neutral with regard to jurisdictional claims in published maps and institutional affiliations.

\section{Ready to submit your research? Choose BMC and benefit from:}

- fast, convenient online submission

- thorough peer review by experienced researchers in your field

- rapid publication on acceptance

- support for research data, including large and complex data types

- gold Open Access which fosters wider collaboration and increased citations

- maximum visibility for your research: over $100 \mathrm{M}$ website views per year

At BMC, research is always in progress.

Learn more biomedcentral.com/submissions 